June 1993

\title{
Carbamazepine-Associated Hyponatremia
}

\author{
University of Connecticut \\ Sandra Dabora, MD, PhD \\ University of Connecticut \\ Rebecca L. Johnson, MD \\ University of Connecticut \\ Michelle B. Riba, MD \\ University of Connecticut
}

Mitchell S. Gandelman, MD, PhD

\section{Follow this and additional works at: https://jdc.jefferson.edu/jeffjpsychiatry \\ Part of the Psychiatry Commons \\ Let us know how access to this document benefits you}

\section{Recommended Citation}

Gandelman, MD, PhD, Mitchell S.; Dabora, MD, PhD, Sandra; Johnson, MD, Rebecca L.; and Riba, MD, Michelle B. (1993) "Carbamazepine-Associated Hyponatremia," Jefferson Journal of Psychiatry. Vol. 11 : Iss. 2 , Article 8.

DOI: https://doi.org/10.29046/JJP.011.2.005

Available at: https://jdc.jefferson.edu/jeffjpsychiatry/vol11/iss2/8

This Article is brought to you for free and open access by the Jefferson Digital Commons. The Jefferson Digital Commons is a service of Thomas Jefferson University's Center for Teaching and Learning (CTL). The Commons is a showcase for Jefferson books and journals, peer-reviewed scholarly publications, unique historical collections from the University archives, and teaching tools. The Jefferson Digital Commons allows researchers and interested readers anywhere in the world to learn about and keep up to date with Jefferson scholarship. This article has been accepted for inclusion in Jefferson Journal of Psychiatry by an authorized administrator of the Jefferson Digital Commons. For more information, please contact: JeffersonDigitalCommons@jefferson.edu. 


\title{
Carbamazepine-Associated Hyponatremia
}

\author{
Mitchell S. Gandelman, M.D., Ph.D., \\ Sandra Dabora, M.D., Ph.D., \\ Rebecca L. Johnson, M.D., \\ and Michelle B. Riba, M.D.
}

\begin{abstract}
Four cases of CBZ-induced or exacerbated hyponatremia are described in middle-aged to elderly females. Two cases are remarkable in that the pretreatment sodium levels demonstrate hyponatremia. A return to prior sodium levels was observed upon the discontinuation of carbamazepine therapy. No definitive conclusions can be drawn from these case reports; however, similarities in the cases can be examined as follows: (1) all four women have medical problems, in particular two patients had pre-existing hyponatremia; (2) all four patients were using concurrent medications; (3) all four women presented psychotic. A literature review examines risk factors, pharmacological mechanism, and the time course for CBZ-induced hyponatremia.
\end{abstract}

Carbamazepine-an iminodibenzyl compound-was introduced into clinical medicine in 1962 (1). Since that time, clinical studies have demonstrated carbamazepine (CBZ) to be effective in the treatment of numerous psychiatric and neurologic disorders such as bipolar disorder $(2,3)$, unipolar depression (3), generalized and psychomotor seizures (4,5), schizophrenia (6), schizoaffective disorder (6), pain syndromes (5,7), and borderline personality disorder (8). Additionally, in 1966 Braunhofer and Zicka reported the antidiuretic effect of (CBZ) in neurohypophysial diabetes insipidus (9). Unfortunately, the antidiuretic effect of CBZ can significantly complicate the effectiveness of CBZ for the treatment of psychiatric disorders by producing hyponatremia. Numerous case reports (10-22), studies (23-32), and two reviews $(33,34)$ have clearly documented the problem; however, little consensus prevails towards understanding either the mechanism or predisposing causes for GBZ-induced hyponatremia.

In this study, we present four women, middle to elderly in age, who demonstrated hyponatremia after a short duration of CBZ therapy. Of significance is the fact that all four women had previous medical complications, and furthermore, two were hyponatremic prior to CBZ therapy. Thus, medical complications, especially a prior abnormality of osmoregulation were observed to be associated with hyponatre-

When this study was written, Dr. Gandelman and Dr. Johnson were residents in the Department of Psychiatry, Dr. Dabora was a third year medical student, and Dr. Riba was an Assistant Professor of Psychiatry at the University of Connecticut. Presently Dr. Gandelman is an Assistant Professor of Psychiatry at Yale University, whereas the other Co-authors are pursuing careers in their chosen medical specialties. 
mia secondary to CBZ therapy in these case reports. However, due to the small number of patients and the uncontrolled nature of this study, we are not suggesting that medical complications, especially in osmoregulation, represent a statistically significant association with CBZ-induced hyponatremia.

\section{CASE REPORTS}

Case I

Mrs. A, a 68 year old woman with a diagnosis of major depression with psychotic features, was admitted to the inpatient psychiatry unit at the University Hospital with a 5 day history of deteriorating symptoms which included: depressed mood, social withdrawal, insomnia, poor appetite, feelings of guilt and hopelessness, mood congruent auditory hallucinations, and religious delusions. The patient had been a nursing home resident for 13 years and had a long history of recurrent major depression with psychotic features and chronic medical problems. On admission, the patient was receiving the following medications: phenobarbital ( $30 \mathrm{mg}$ each morning and $60 \mathrm{mg}$ at night), trazodone $200 \mathrm{mg}$ at night time, diazepam $5 \mathrm{mg}$ three times daily and NPH insulin 12 units every morning. Admitting labs were as follows: serum sodium $131 \mathrm{meq} / \mathrm{l}$, (hyponatremic); serum chloride $98 \mathrm{meq} / \mathrm{l}$, serum potassium $4.5 \mathrm{meq} / \mathrm{l}$, serum $\mathrm{CO}_{2}$ $28 \mathrm{meq} / \mathrm{l}$, blood urea nitrogen $6 \mathrm{mg} / \mathrm{dl}$, serum creatinine $0.6 \mathrm{mg} / \mathrm{dl}$, serum glucose $102 \mathrm{mg} / \mathrm{dl}$, and phenobarbital level $25 \mathrm{mg} / \mathrm{l}$. Liver function tests, hematologic, and thyroid studies were normal. A head CT scan revealed some cerebral and cerebellar atrophy as well as an old infarct in the left frontoparietal lobe. An EEG showed diffuse symmetric and excessive fast activity, but no epileptiform foci.

Phenobarbital was tapered slowly, and then CBZ was started to treat both the seizure disorder and the affective illness, and titrated to a dosage of $600 \mathrm{mg}$ per day. The patient was medically stable during the change-over period and was therapeutic on CBZ after several days (level of $7 \mathrm{mg} / \mathrm{l}$ ). Since the patient was still complaining of auditory hallucinations, haloperidol $2 \mathrm{mg}$ three times daily was added to the regimen. One week later, this patient was in an acute confusional state, oriented only to person, drowsy, incontinent of urine, had slurred speech, and could no longer remember the names of staff members. Laboratory studies revealed that the patient's serum sodium level had dropped significantly to $119 \mathrm{meq} / \mathrm{l}$. All remaining laboratory studies were unremarkable including the CBZ level $(7 \mathrm{mg} / \mathrm{l})$. The serum osmolality on the following day was $247 \mathrm{mOsm} / \mathrm{kg}$ (normal $=275-295 \mathrm{Mosm} / \mathrm{kg}$ ) and urine osmolality measured 2 days later was $255 \mathrm{Mosm} / \mathrm{kg}$ with a urine sodium of $68 \mathrm{meq} / \mathrm{l}$. The CBZ was discontinued and the patient was fluid restricted. Due to the patient's past history of a seizure disorder, the patient was started on phenytoin which was titrated up to a dose of $200 \mathrm{mg}$ twice daily. The delirium cleared to her previous baseline mental status two days after stopping the CBZ, and the serum sodium gradually increased to $133 \mathrm{meq} / \mathrm{l}$ over the next week.

\section{Case II}

Mrs. B, an 80 year old women, with an approximate 60 -year history of bipolar disorder, presented to the emergency room experiencing a relapse of her primary affective disorder. On presentation, the patient described a 1 week history of a hypomanic episode consisting of the following symptoms: middle insomnia, elevated mood, grandiose ideation, increased energy, and increased sexual preoccupation. In addition, she described drinking approximately 1 
alcoholic drink per day. Prior to admission the patient's medications included: lovastatin $1 \mathrm{mg}$ twice daily, and triavil 2-10 (2 mg perphenazine and $10 \mathrm{mg}$ amitriptyline) one tablet in the morning and two tablets at night.

On admission the patient's manic episode was controlled with low doses of both haloperidol and lorazepam. Admission labs revealed the following: sodium of $134 \mathrm{meq} / \mathrm{l}$ (hyponatremic), potassium of $4.5 \mathrm{meq} / \mathrm{l}$, chloride $99 \mathrm{meq} / 1, \mathrm{CO}_{2} 27 \mathrm{meq} / \mathrm{l}$, glucose $104 \mathrm{mg} / \mathrm{dl}$, creatine $0.7 \mathrm{mg} / \mathrm{dl}$ and blood urea nitrogen $11 \mathrm{mg} / \mathrm{dl}$, normal liver function tests, normal thyroid and hematology studies. CBZ treatment was initiated and titrated to $200 \mathrm{mg}$ twice daily; however, three days after initiating CBZ, the patient tripped and suffered a mild contusion of her left forehead. Laboratory and radiologic studies were ordered with the following results: sodium $125 \mathrm{meq} / \mathrm{l}$, potassium $4.8 \mathrm{meq} / 1$, chloride $91 \mathrm{meq} / 1, \mathrm{CO}_{2} 26 \mathrm{meq} / \mathrm{l}$, and a normal head CT scan. Attempts were made to continue the CBZ treatment while managing this acute exacerbation of the hyponatremia with fluid restriction, $1500 \mathrm{ml} /$ day. The patient's sodium level fluctuated between 122 and $131 \mathrm{meq} / 1$ with serum osmolality of $265 \mathrm{mOsm} / 1$, requiring the discontinuation of CBZ 11 days after initiation. Over the next 2 weeks the patient's sodium levels followed an upward trend and at discharge, the level was $133 \mathrm{meq} / \mathrm{l}$.

\section{Case III}

Mrs. C, a 54 year old mentally retarded female, with a long history of chronic undifferentiated schizophrenia requiring numerous hospitalizations, was transferred from a small community hospital to the University Hospital. The schizophrenia had been managed effectively with antipsychotic medication; however, due to the fact that the patient's prior symptoms suggested a neuroleptic malignant syndrome (elevated temperature of $100^{\circ} \mathrm{F}$ and creatine kinase of $343 \mathrm{U} / \mathrm{l})$ the physicians at the community hospital felt uncomfortable managing the patient with neuroleptics. Her medications on transfer were as follows: thioridazine $25 \mathrm{mg}$ twice daily, clonazepam $1 \mathrm{mg}$ twice daily, alprazolam $0.25 \mathrm{mg}$ three times daily, dicloxacillin sodium $500 \mathrm{mg}$ four times daily, glipizide $25 \mathrm{mg}$ daily, sodium docusate 200 $\mathrm{mg}$ daily, and iron sulfate $325 \mathrm{mg}$ twice daily.

On presentation the patient was highly agitated, required four point restraints, and remained acutely psychotic. The patient was initially managed with lorazepam, $1 \mathrm{mg}$ three times daily, glyburide $2.5 \mathrm{mg}$ daily, iron sulfate $325 \mathrm{mg}$ twice daily, and docusate $100 \mathrm{mg}$ twice daily. Admission laboratory values were as follows: glucose $124 \mathrm{mg} / \mathrm{dl}$, urea nitrogen $11 \mathrm{mg} / \mathrm{dl}$, creatinine $1.0 \mathrm{mg} / \mathrm{dl}$, sodium $142 \mathrm{meq} / \mathrm{l}$, potassium $4.4 \mathrm{meq} / \mathrm{l}$, chloride $105 \mathrm{meq} / 1, \mathrm{CO}_{2} 27$ meq/l, ionized calcium 1.37 mmole/l (slightly elevated). The liver function tests, thyroid function, and hematologic laboratory studies were all within the normal range. A neurological work up revealed a normal EEG and head CT scan. One week following the neurological evaluation, the patient experienced two generalized tonic clonic seizures each under 60 seconds. A more in depth neurological evaluation was initiated; however, again all results were normal. CBZ was started and the doses were increased slowly over a four week period until a therapeutic level of $8.0 \mathrm{mg} / \mathrm{l}$ was obtained. Approximately two weeks after reaching a therapeutic level, a sodium of $127 \mathrm{meq} / \mathrm{l}$ was noted. The patient complained of being light headed and having difficulty ambulating. During this period of hyponatremia, urine osmolality was $447 \mathrm{mOsm} / \mathrm{kg}$ and serum osmolality was $267 \mathrm{mOsm} / \mathrm{kg}$ (normal range 275-295). Phenytoin was substituted for CBZ and within one week the patient's sodium normalized. 
Case IV

Mrs. D, a 58 year old white female, with an approximately 20 -year history of a schizoaffective disorder was admitted to the University Hospital after an acute exacerbation of her psychotic illness. The patient's schizoaffective disorder had been managed with low dose neuroleptics, fluphenazine 5-10 mg per day and lithium carbonate. Six months prior to the admission, she described a progressive return of typical symptoms: isolation, persecutory delusions, messages from the television, delusions of reference, poor concentration, insomnia, poor appetite, low mood, lethargy, and suicidal ideation. On presentation the patient was irritable, anxious, and guarded. The admission laboratory evaluation; sodium $143 \mathrm{meq} / \mathrm{l}$, glucose $117 \mathrm{mg} / \mathrm{dl}$, potassium $4.4 \mathrm{meq} / \mathrm{l}$, chloride $116 \mathrm{meq} / \mathrm{l}, \mathrm{CO}_{2} 22 \mathrm{meq} / \mathrm{l}$, liver function tests, thyroid studies, and hematology studies; was normal.

She was initially managed with fluphenazine $5.0 \mathrm{mg}$ twice daily and then switched to molindone $20 \mathrm{mg}$ twice daily, benztropine $1.0 \mathrm{mg}$ on an as needed basis, and lorazepam $1.0 \mathrm{mg}$ on an as needed basis. Due to the refractory nature of Mrs. C's thought disorder, CBZ was added and increased to $200 \mathrm{mg}$ three times daily. Routine laboratory studies were ordered 5 days after having reached a CBZ dose of $200 \mathrm{mg}$ three times daily, and were significant for a sodium of $122 \mathrm{meq} / \mathrm{l}$, creatinine $0.8 \mathrm{mg} / \mathrm{dl}$, potassium $4.5 \mathrm{meq} / \mathrm{l}$, chloride $90 \mathrm{meq} / \mathrm{l}$ and $\mathrm{CO}_{2} 24$ meq/l. The CBZ was discontinued secondary to the hyponatremia and after 1 week the patient's hyponatremia resolved.

\section{DISCUSSION}

In this paper, we report 4 cases of CBZ-associated hyponatremia in four middle-aged to elderly females, all who have medical complications. Two cases are remarkable in that the pretreatment sodium levels demonstrate hyponatremia; however, even these low sodium levels were significantly decreased by CBZ. Due to the fact that these are isolated reports, few definitive conclusions can be made, although similarities in these cases should be examined. First, all patients are middle-aged to elderly females. Second, all four women have medical problems; furthermore, two have abnormal osmoregulation as defined by pre-existing hyponatremia. Third, all patients were using concurrent medications, especially antipsychotic medications, and all presented with psychotic symptoms. These case studies highlight the fact that CBZ-induced hyponatremia represents a serious side effect which may not be as rare as previously thought.

Numerous cases, mostly associated with neurological disorders, describing CBZinduced hyponatremia have been reported in the literature over the past 20 years (10-22). Again no conclusions can be drawn due to the small sample size; however, some generalizations can be described. First, most patients appear to be over 40 years old; although a case report by Palladino (15) describes a 20 year old male with hyponatremia. Second, all patients are suffering from a neurological/psychiatric disease. Third, many of the patients are taking other medications in conjunction with CBZ. Fourth, the time period required for the onset of hyponatremia following initiation of CBZ therapy is difficult to ascertain, as many of the case reports deal with long term administration of CBZ. Fifth, recovery from hyponatremia occurs following withdrawal of CBZ. In summary, the pooled quantitative data from the case 
reports are as follows: range of age was from 20 to 80 years, range of CBZ per day was between 400-1200 mg, and levels ranged from 4.4 to 15 micrograms per liter.

Even in larger clinical studies (23-32), few definitive conclusions can be made concerning CBZ-induced hyponatremia, since the data among studies are often contradictory. Again for the same reason cited above minimal data exists on the time course of CBZ-induced hyponatremia. The overall incidence rate of CBZ-induced hyponatremia is difficult to ascertain, since the study populations from the many articles are not homogeneous. Thus, the data can not be summed, and a range of $0-33 \%$ for the incidence rates of CBZ-induced hyponatremia is the only descriptive statistic which can be reported.

The symptoms of hyponatremia or water intoxication when plasma sodium falls below 120 milliequivalent per liter (meq/l) include: dizziness, headache, lethargy, mental confusion, mental slowing, weakness, loss of apatite, and hostility. Neurological abnormalities, stupor, convulsions, and coma, dominate as the sodium level falls below $110 \mathrm{meq} / \mathrm{l}$ (33). Much of the difficulty concerning the identification of CBZ-induced hyponatremia involves the high percentage of asymptomatic individuals with hyponatremia. In this case report, only half the patients were symptomatic, and in other case reports by O'Hare et al. (30) and Kalff and coworkers (22) even the most severely affected hyponatremic patients were asymptomatic. An additional complication in the clinical diagnosis of CBZ-induced hyponatremia occurs from the overlap of symptoms relating to CBZ intoxication. In summary, few definitive facts can be ascertained about the side effect of CBZ-induced hyponatremia. First, the time course of CBZ-induced hyponatremia is poorly defined and may occur after chronic exposure. Second, the incidence rate varies from $0-33 \%$. Third, hyponatremia has clearly defined symptoms; however many patients remain asymptomatic at sodium levels below $116 \mathrm{meq} / \mathrm{l}$.

An examination of the CBZ-induced hyponatremia literature reveals numerous studies with little concurrence on either risk factors or mechanism of CBZ-induced hyponatremia. For example, studies by Kalff and coworkers (22) and Lahr (23) identify age as an important risk factor; whereas numerous studies (24-31) do not demonstrate a correlation between age and CBZ-induced hyponatremia. Similarly, CBZ serum levels have been associated with hyponatremia in studies by Henry and coworkers (27), Lahr (23), Kalff and colleagues (22), O’Hare and associates (30), while Helin and coworkers (25), Joffe and associates (29), and Vieweg and coworkers (32) have not observed a relationship between CBZ serum levels and hyponatremia. Lastly, only Kalff and coworkers (22) and Yassa and colleagues (31) describe an association of polypharmacy and CBZ-induced hyponatremia. Thus, even an exploration of the previously completed studies on CBZ-induced hyponatremia fails to consistently reveal risk factors for the development of CBZ-induced hyponatremia.

In a similar manner, the studies examining the pharmacological mechanisms responsible for $\mathrm{CBZ}$-induced hyponatremia fail to elucidate any general consensus. One could speculate on the mechanisms of CBZ-induced hyponatremia, i.e., CBZinduced hypersecretion of anti-diuretic hormone (ADH), a direct action of $\mathrm{CBZ}$ on renal tubules, a positive synergistic action of $\mathrm{CBZ}$ and $\mathrm{ADH}$ on renal tubules, a 
CBZ-induced decrease in osmoreceptor sensitivity to sodium, or lastly a CBZ-induced resetting of the osmoreceptor threshold for sodium. Frahm and colleagues (35), Kimura and associates (36), and Ashton and coworkers (10) present evidence consistent with a CBZ-induced hypersecretion of ADH; however, both Frahm and coauthors (35) and Kimura and colleagues (36) use a bioassay, the hydrated rat, which measures activity and not concentration of ADH. Conversely, Kalff and associates (22), Gold and coworkers (37), Stephens and coauthors (38), Meinders and colleagues (39) and Thomas and associates (40) do not support the finding that CBZ increases $\mathrm{ADH}$ secretion. Furthermore, these studies employ radioimmunoassay (RIA) which attempts to directly determine the concentration of $\mathrm{ADH}$, and consequently, these studies contain a more reliable assay for $\mathrm{ADH}$ as compared with a bioassay. Meinders and associates (39) conclude in their study that CBZ sensitizes or acts directly on the renal tubules to produce a positive synergistic effect with $\mathrm{ADH}$. A decrease in osmoreceptor sensitivity to sodium (the lazy receptor hypothesis) was consistent with the data from independent studies done by both Gold and coauthors (37) and Stephens coworkers (38). In addition, these two studies proposed that CBZ may also have a direct effect on renal tubular cells. Conversely, Thomas and associates (40) deduced from their data that CBZ resets the osmoreceptor threshold for $\mathrm{ADH}$ and does not affect the sensitivity of the osmoreceptor. The most probable mechanism of CBZ-induced hyponatremia involves some type of CBZ-directed osmoreceptor perturbation, since the studies implicating this mechanism were more rigorous and completed with more modern assay methodology. However, two of the studies that implicate CBZ-directed osmoreceptor dysfunction, also reveal concurrent evidence of a CBZ effect on renal tubular cells. At present the etiology and risk factors associated with CBZ-induced hyponatremia remain poorly defined, and thus, further studies will be needed to elucidate the mechanism of CBZ-induced hyponatremia.

Our interest in this topic was initially stimulated by four interesting cases. Although all four cases had numerous factors in common; such as female sex, chronic medical problems (including pre-existing hyponatremia), concurrent use of medications (especially antipsychotic medications), and initial psychotic presentation; the literature does not support any of these characteristics as risk factor for developing CBZ-induced hyponatremia. Two of the four patients were asymptomatic with sodium levels below $130 \mathrm{meq} / \mathrm{l}$, an observation commonly noted in the literature. Consequently, electrolyte monitoring of patients taking CBZ is necessitated. In conclusion, the case reports, clinical studies, and mechanistic studies often yield conflicting data concerning CBZ-induced hyponatremia; however, the occurrence of CBZ-induced hyponatremia is well documented, and thus, physicians using CBZ must monitor (both clinically and with electrolyte studies) their patients for this dangerous side effect.

\section{REFERENCES}

1. Blom S: Trigeminal Neuralgia: Its treatment with a new anticonvulsant drug. Lancet 1962; $1: 839-840$ 
2. Ballenger JC, Post RM: Carbamazepine in manic depressive illness: a new treatment. Am J Psychiatry 1980; 137:782-790

3. Ballenger JC: The clinical use of carbamazepine in affective disorders. J Clin Psychiatry 1988; 49(4, Suppl):13-19

4. Dalby MA: Antiepileptic and psychotropic effect of carbamazepine (Tegretol) in the treatment of psychomotor epilepsy. Epilepsia 1971; 12:325-334

5. Sillanpaa M: Carbamazepine, pharmacology and clinical uses. Acta Neurol Scand 1981; 64(88, Suppl):111-202

6. Neppe VM: Carbamazepine in nonresponsive psychosis. J Clin Psychiatry 1988; 49(4, Suppl):22-28

7. Ekblom K: Tegretol, a new therapy of tabetic lightening pains. Preliminary Report. Acta Med Scand 1966; 179:251-252

8. Gardner DC, Cowdry RW: Positive effects of carbamazepine on behavioral dyscontrol in borderline personality disorder. Am J Psychiatry 1986; 143:519-522

9. Braunhofer J, Zicka L: Eroffnet Tegretal Neue therapiemoglichkeiten be: bestimmten neurologischen and endokrinen krankhertsbilder. Medizinische Welt 1966; 17:1875-80

10. Ashton MG, Ball SG, Thomas TH, Lee MR: Water intoxication associated with carbamazepine treatment. Brt MedJ 1977; 1:1134-1135

11. Byrne E, Wong CH, Chambers DG, Rice JP: Carbamazepine therapy complicated by nodal bradycardia and water intoxication. Aust N Z J Med 1979; 9:295-296

12. Flegel KM, Cole CH: Inappropriate antidiuresis during carbamazepine treatment. Ann Int Med 1977; 87:722-723

13. Gadish DB: Hyponatremic effect of carbamazepine. J Clin Psychiatry 1987; 48:173-4

14. Juergens SM, Milliner DS, Lee ME: Carbamazepine and hyponatremia. Am J Psychiatry 1986; 143:1328-1329

15. Palladino A: Hyponatremia associated with carbamazepine therapy. Am J Psychiatry 1986; 143:1190

16. Ponte CD, Pollard S, Dattola RK: A suspected case of carbamazepine-induced hyponatremia. J Fam Prac 1990; 31:664-667

17. Rado JP: Water intoxication during carbamazepine treatment. Brt Med J 1973; 1:479

18. Scoccia B, Scommegna A: Carbamazepine-induced hyponatremia after transabdominal follicular ultrasound examination. Fertility Sterility 1988; 50:984-985

19. Sordillo P, Sagransky DM, Mercado R, Michelis MF: Carbamazepine-induced syndrome of inappropriate antidiuretic hormone secretion. Arch Intern Med 1978; 138:299-301

20. Singh AN: Fluid retention during treatment with carbamazepine. Can Med Assoc J 1978; 118:24

21. Smith NJ, Espir MLE, Baylis PH: Raised plasma arginine Vasopressin concentration in carbamazepine-induced water intoxication. Brt Med J 1977; 2:804

22. Kalff R, Houtkooper MA, Meyer WA, et al: Carbamazepine and serum sodium levels. Epilepsia 1984; 25:390-397

23. Lahr MB: Hyponatremia during carbamazepine therapy. Clin Pharmacol Ther 1985; 37:693-696

24. Uhde TW, Post RM: Effects of carbamazepine on serum electrolytes: Clinical and theoretical implications. J Clin Psychopharm 1983; 3:103-106

25. Helin I, Nilsson KO, Bjerre I, Vegfors P: Serum sodium and osmolality during carbamazepine treatment in children. Brt Med J 1977; 2:558

26. Perucca E, Garratt A, Hebdige S, Richens A: Water intoxication in epileptic patients receiving carbamazepine. J Neurol Neurosurg Psychiatry 1978; 41:713-718 
27. Henry DA, Lawson DH, Reavey P, Renfrew S: Hyponatremia during carbamazepine treatment. Brit Med J 1977; 1:83-84

28. Emsley RA, Van de Meer H, Aalbers C, Taljaard, JJF: Inappropriate antidiuretic state in long term psychiatric inpatients. S. Afr Med J 1990; 77:307-308

29. Joffe RT, Post RM, Unde TW: Effects of carbamazepine on serum electrolytes in affectively ill patients. Psychological Med 1986; 16:331-335

30. O'Hare J, O'Driscoll D, Duggan B, Callaghan N: Hyponatremia and carbamazepine intoxication. Irish J Med Sci. 1980; 149:10-14

31. Yassa R, Iskandar H, Nastase C, Cemille Y: Carbamazepine and hyponatremia in patients with affective disorder. Am J Psychiatry 1988; 145:339-342

32. Vieweg V, Glick JL, Herring S, et al: Absence of carbamazepine-induced hyponatremia among patients also given lithium. Am J Psychiatry 1987; 144:943-947

33. Kato DB: Dilutional hyponatremia and water intoxication during carbamazepine therapy. Drug Intelligence and Clin Pharm 1978; 12:392-396

34. Gandelman MS: Review of Carbamazepine-induced hyponatremia. Prog. Neuro-Psychopharmacol. \& Biol. Psychiat. (in press)

35. Frahm H, Smejhal E, Kratzenstein R: Antidiuretic effect of an anticonvulsant drug. Acta Endocrinol (Kbh) 1969; 138(Suppl):240

36. Kimura T, Matsui K, Sato T, et al: Mechanism of carbamazepine (Tegretol)-induced antidiuresis: evidence for release of antidiuretic hormone and impaired excretion of a water load. J Clin Endocrinol Metab 1974; 38:356-362

37. Gold PW, Robertson GL, Ballenger JC, et al: Carbamazepine diminishes the sensitivity of plasma arginine vasopressin response to osmotic stimulation. J Clin Endocrin Metab 1983; $57: 952-957$

38. Stephens WP, Coe JY, Baylis PH: Plasma arginine vasopressin concentrations and antidiuretic action of carbamazepine. Brit Med J 1978; 1:1445-1447

39. Meinders AE, Cejka V, Robertson GL: The antidiuretic action of carbamazepine in man. Clin Sci Molec Med 1974; 47:289-299

40. Thomas TH, Ball SG, Wales JK, et al: Effect of carbamazepine on plasma and urine arginine-vasopressin. Clin Sci Molec Med 1978; 54:419-424 